\title{
Matrimonio y estructura de la élite en la Florencia
} Renacentista, 1282-1500 ${ }^{1}$

\author{
John F. Padgett - Universidad de Chicago², USA
}

\section{Resumen}

Este texto, derivado de una ponencia en una conferencia, es un informe preliminar de un proyecto a larga escala para trazar las transformaciones en las estructuras de las redes de la élite florentina a lo largo de dos siglos. En este artículo me limito únicamente a la descripción de tendencias anteriores, desconocidas en modelos amplios, de los matrimonios cruzados florentinos. Los lectores informados verán inmediatamente que dichas tendencias tienen implicaciones importantes para los debates en la historiografía florentina (que desarrollaré más adelante). En último término, estoy interesado en las implicaciones políticas de las tendencias aquí descritas. Pero por ahora no entro en una interpretación, explicación o argumentación. Trataré únicamente de mostrar hechos nuevos.

Palabras clave: Movilidad social - Familia - Historia - Matrimonio.

\section{Abstract}

This conference paper is an interim report from a large-scale project to trace transformations in Florentine elite network structures over two centuries. In this paper, I confine myself solely to a description of previously unknown trends in broad patterns of Florentine inter-marriage. Knowledgeable readers will immediately see that these trends have important implications for debates in Florentine historiography (which I will develop in the future). Ultimately, I am primarily interested in the political implications of the trends I herein describe. But for now I do not engage in interpretation, explanation, or argumentation. I intend simply to lay out some new facts.

Key words: Social Mobility - Family - History - Marriage.

\footnotetext{
${ }^{1}$ Traducción realizada por Ainhoa de Federico y Lola de la Rúa

${ }^{2}$ Enviar correspondencia a: John F. Padgett jpadgett@midway.uchicago.edu
} 
REDES- Revista hispana para el análisis de redes sociales

Vol.21,\#3, Diciembre 2011

http://revista-redes.rediris.es

Este texto, derivado de una ponencia en una conferencia, es un informe preliminar de un proyecto a larga escala para trazar las transformaciones en las estructuras de las redes de la élite florentina a lo largo de dos siglos. En este artículo me limito únicamente a la descripción de tendencias anteriores, desconocidas en modelos amplios, de los matrimonios cruzados florentinos. Los lectores informados verán inmediatamente que dichas tendencias tienen implicaciones importantes para los debates en la historiografía florentina (que desarrollaré más adelante). En ultimo término, estoy interesado en las implicaciones políticas de las tendencias aquí descritas. Pero por ahora no entro en una interpretación, explicación o argumentación. Trataré únicamente de mostrar hechos nuevos. En particular, mi falta de referencia a literatura secundaria relevante [un error a corregir en borradores futuros] no debería ser tomado como un indicador de mi falta de conocimiento de dichos trabajos excelentes.

\section{Datos y fuentes}

La base de datos, de la cual sólo se utiliza una parte aquí, comprende probablemente la colección más extensa de redes históricas jamás reunida. El objetivo eventual de este proyecto, como para escribir un libro, no es otro que realizar los Anales de la "historia total" de las transformaciones combinadas de las estructuras sociales, económicas y políticas florentinas a lo largo de dos siglos. Huelga decir que este objetivo es únicamente concebible gracias a la sorprendente riqueza de los archivos florentinos y por la impresionante diligencia de muchos historiadores florentinos además de mi. Los datos pueden ser descritos en cinco partes: redes de matrimonios, redes económicas, otras redes sociales, información atributiva y pertenencias a partidos y facciones.

Se han recogido y computerizado unos 10.500 datos de matrimonios entre familias de apellidos florentinos en el periodo 1282-1500 a partir de una gran variedad de fuentes. Viajando para conocer seis colecciones excepcionales de libros en Estados Unidos, codifiqué y computericé 38 árboles familiares florentinos del Renacimiento a partir de las excelentes genealogias de principos del siglo diecinueve de las celebradas familias italianas compiladas por Pompeo Litta y Luigi Passerini. A través de dos viajes separados de un mes al Archivio di Stato en Florencia, codifiqué y digitalicé los matrimonios de 298 familias de menor renombre de la compilación de 13 volúmenes de Pierantonio dell'Ancisa, quien trabajó a mediados del 16. Estas compilaciones se basaban, por su parte, en series de contratos de notarios (p.e. relativos a las dotes) la mayoría de los cuales ahora están perdidos. Además, codifiqué y digitalicé 12 árboles familiares de una variedad de historiadores 
REDES- Revista hispana para el análisis de redes sociales

Vol.21,\#3, Diciembre 2011

http://revista-redes.rediris.es

disponibles en Estados Unidos. En total codifiqué tantos matrimonios como pude encontrar en las fuentes para 335 clanes familiares. (Los números no cuadran a causa de codificaciones múltiples). Dado que codifiqué todos los matrimonios implicados en estos 335 clanes familiares, el número total de familias representadas en esta base de datos es mucho mayor. (Tengo información atributiva de 960 familias; por lo tanto 960 es el límite efectivo de la muestra. En la mayoría de los análisis mostrados aquí se analizan 500-600 clanes familiares cada vez).

Los detalles del muestreo, codificación y fuentes de error serán enunciados en documentos futuros. De momento, digamos que se utilizó un muestreo por bola de nieve a través de múltiples viajes a los archivos. Dado el porcentaje de cobertura que se logró eventualmente, la crítica estadística habitual al muestreo por bola de nieve no tiene mucho sentido aquí. Como se muestra en la figura 1 , que relaciona estos matrimonios a varios censos de impuestos de la población florentina total (que describimos más abajo), estimo que mi muestra de más de 10.000 cubre un $40 \%$ de todos los matrimonios que se llevaron a cabo entre las familias con apellidos. A causa principalmente de las fuentes, y en segundo lugar a la técnica de muestreo, el porcentaje de cobertura declina conforme el estatus social decrece. En la parte superior de la escala el porcentaje de cobertura para los 500 hogares más ricos de la ciudad crece de $65 \%$ al $90 \%$ a lo largo del tiempo, tal como se muestra en la figura 1.

Las redes económicas no figuran en este documento, pero mencionaré brevemente dos bases de datos que han sido reunidas hasta ahora. Un estudiante mío avanzado, Paul McLean, ha codificado y digitalizado desde el catasto de impuestos de 1427 (esencialmente I.R.S- tipo devolución de impuestos) unas 14.000 relaciones de deuda - es decir, quien debe dinero a quién, por qué tipo de transacción anterior. Esta codificación diacrónica fue realizada en su primera oleada en la Universidad de Chicago, utilizando una copia microfilmada depositada allí por el David Herlihy tardío, y en oleadas posteriores por Paul en el Archivio di Stato, para suplir lagunas en el microfilm.

Paul y yo también hemos reunido datos de asociados económicos a lo largo del tiempo. A partir de registros gremiales en el Archivio di Stato, he recogido (pero todavía no digitalizado) una serie de tiempo casi completa de todos los asociados y empresas en una industria - la banca - a lo largo del periodo 1340 a 1480. A partir del catasto de 1427, McLean ha recogido y digitalizado esencialmente un censo de todos los asociados y empresas de la ciudad, en todas las industrias. Y para el 
REDES- Revista hispana para el análisis de redes sociales

Vol.21,\#3, Diciembre 2011

http://revista-redes.rediris.es

1451, Anthony Molho ha publicado una lista casi completa de asociados y empresas de todas las industrias. Anticipamos que encontraremos mucha información valiosa sobre las estructuras cambiantes del mercado, las industrias y las empresas en estas fuentes de datos en futuras publicaciones (conjuntas y otras).

$$
\begin{gathered}
8 / 20 / 94 \\
\text { (offth } 1994 \text { trip) }
\end{gathered}
$$

\%o Maniage Covnage in Sample

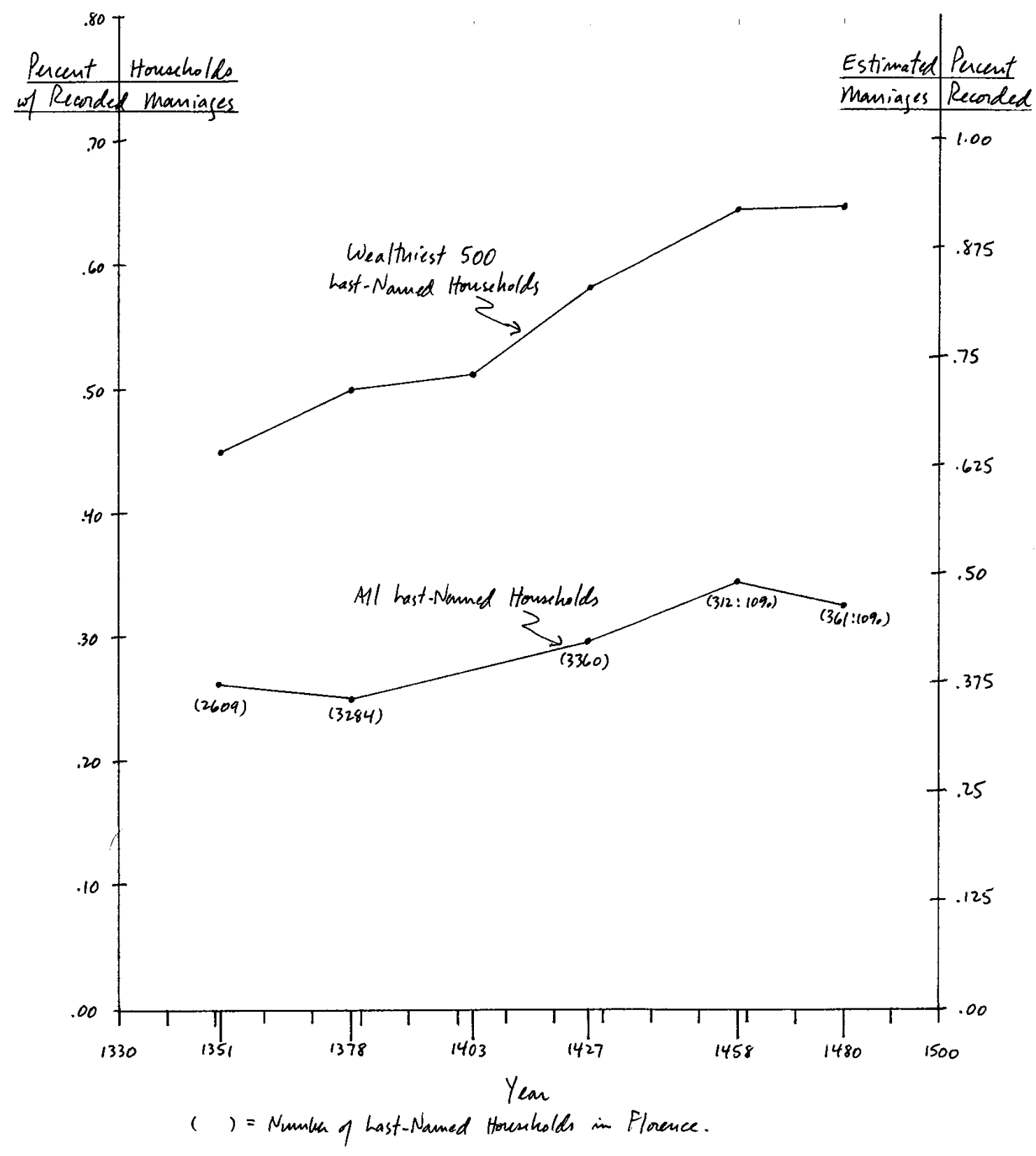

Figura 1. Porcentaje de matrimonios cubiertos por la muestra. 
REDES- Revista hispana para el análisis de redes sociales

Vol.21,\#3, Diciembre 2011

http://revista-redes.rediris.es

Bajo el tema de "otras redes sociales" hay dos tipos de elementos: (1) a partir de una rica fuente secundaria prosopográfica, un libro de Dale Kent llamado The rise of the Medici, un colega anterior, Christopher Ansell, y yo codificamos nueve tipos diferentes de relaciones sociales, miembros de partidos políticos, para el periodo 1420-1434. Los análisis de estos datos han sido ya expuestos en un artículo en 1993 en el American Journal of Sociology. (2) Para su tesis doctoral, Paul McLean ha reunido, transcrito y codificado 869 cartas de patrocinio, en las que se solicitan favores de distintos tipos. Paul mismo informará de estos documentos ricos de textura cualitativa en publicaciones futuras.

Además de estos datos de redes sociales sistemáticos, a lo largo del tiempo he recogido y digitalizado una variedad de datos atributivos de cada uno de los 960 clanes familiares que he detectado en los matrimonios florentinos en algún momento a lo largo del periodo de dos siglos. (Un cierto número de estas familias, por supuesto, entran y salen de la historia a lo largo del tiempo). A menudo, pero no siempre, puedo desagregar más el nivel de análisis hasta el hogar. Estos datos atributivos pueden ser resumidos en tres categorías: estatus social, riqueza y residencia.

A lo largo de este periodo de república, los florentinos juzgaban el estatus social familiar por cuan políticamente antiguo era - es decir, por la fecha en que el primer miembro de la familia era admitido en el Priorato, es decir, en el cuerpo gobernante de Florencia. Najemy y Kent han publicado esta información sobre muchas familias. Una lista más exhaustiva es la de los volúmenes de mecatti del siglo dieciocho, localizados en las colecciones especiales de la Biblioteca Newberry en Chicago. Esta fuente no sólo contiene más fechas iniciales de familias que Najemy y Kent, sino que también contiene las fechas para cada Prior que cada familia tuvo en toda la historia. En otras palabras, registra las historias políticas de toda la participación de las familias en el gobierno. Esta información ha sido codificada y digitalizada para cada una de los 960 clanes familiares de mi base de datos.

Como es bien sabido entre los historiadores florentinos, los Magnates eran una categoría especial importante de familias socialmente antiguas y prestigiosas que estaban legalmente impedidas para participar en las los cargos públicos. Lansing provee una tabulación de sus identidades.

Los datos de riqueza a lo largo del tiempo para tantos hogares y clanes es muy difícil de obtener, pero con la ayuda de otros historiadores florentinos, se han digitalizado actualmente numerosos censos de impuestos. El catasto de 1427 fue digitalizado y puesto generosamente a disposición del público por el David Herlihy 
REDES- Revista hispana para el análisis de redes sociales

Vol.21,\#3, Diciembre 2011

http://revista-redes.rediris.es

tardío y por Christiane Klapisch. Ellos también digitalizaron una muestra del $10 \%$ de los catasti de 1458 y 1470 . Samuel Cohen me dio sus copias microfimadas del estimo de 1351 y del prestanze de 1378, de los que he transcrito y digitalizado (con mucho esfuerzo) las familias con apellidos. Lauro Martines y Anthony Molho publicaron, en apéndices de sus libros, los 500 hogares más ricos del prestanze de 1403 y del catasti de 1480 respectivamente. [Julius Kirshner y Anthony Molho también han digitalizado el catasto entero de 1480. Tal vez me garanticen acceso a él en el futuro]. La suma total de estos documentos me da una serie temporal de riqueza para 1351 (completa), 1378 (completa), 1403 (parcial), 1427 (completa), 1458 (parcial) y 1480 (parcial).

La información recogida por mí de estas fuentes de impuestos es como sigue: o bien valoración de impuestos o riqueza declarada (dependiendo del documento) del cabeza de familia, residencia del cabeza de familia (al nivel del gonfaloni o de la sala), y para los censos completos, número de hogares por clan familiar. La riqueza y la residencia, por supuesto, pueden ser agregados al nivel total del clan. La dispersión de la residencia del clan a lo largo de los gonfaloni es una medida util de la "cohesión" del clan o de la "solidaridad" (al menos como un primer indicador), que puede ser seguido a lo largo del tiempo. La información de la residencia anterior a 1351, de muchas familias, está contenida en las tablas de Raveggi et al.

Finalmente, los miembros de facciones o partidos políticos han sido codificados, principalmente a partir de fuentes secundarias. Raveggi et al. proveen listas de miembros de güelfos vs. gibelinos (alrededor del 1260) y de Negros vs. Blancos (en los 1300 y 1310). A partir del texto sobre el libro de Brucker la composición de las facciones de los Albizzi y los Ricci (los 1340 y 1350) han sido identificadas. Najemy provée información util sobre los apoyos y oponentes de la élite y de la rebelión de los Ciompi (1378). D. Kent da una lista de apoyos de los Medici a partir de ahí. Sapori también ha publicado una lista de 1449 partisanos de los Medici. En el Bollettino Senese di Storia Patria de 1964 hay una re-publicación de la lista de los firmantes que es útil para identificar a los anti-Medici en 1466. Sólo no se han identificado y digitalizado los anti-Medici de los periodos de revuelta Pazzi tardíos (años 1470) y Savonarola (años 1490). 
REDES- Revista hispana para el análisis de redes sociales

Vol.21,\#3, Diciembre 2011

http://revista-redes.rediris.es

\section{Concentración de la élite}

Un punto de partida conveniente para trazar tendencias amplias en los intercasamientos florentinos es focalizarse en el grado en que la élite florentina, en su conjunto, fue centralizada o concentrada - es decir, el grado en que había desigualdades agudas en las diversas centralidades individuales en el matrimonio, en las redes de diversas familias. Cuanto mayor es la desigualdad entre las familias, más concentrado el núcleo dentro de la élite.

Dos medidas estandar de centralidad relativa en las redes son: (a) el grado - es decir, el número relativo de relaciones / matrimonios en que una familia se implicaba en cada periodo de tiempo y (b) intermediación - es decir, el número relativo (más corto) de "caminos" conectados entre todos los otros pares de familia en la red en que una familia focal está situada. Las medidas de grado significan, esencialmente, la demografía de la situación. Eliminando las grandes disparidades en los ratios de matrimonios, se trata de un proxy para el tamaño del clan - el número de hijos e hijas elegibles que tenía el clan. La intermediación es un concepto más estructural. Si los recursos o la comunicación fluyen en una red, entonces la "intermediación" mide el porcentaje de flujos entre los demás que una familia focal puede interceptar (o bloquear). Por este motivo, se interpreta a menudo como una medida de posición de "poder".

En varios periodos de tiempo, dichas medidas fueron calculadas para todas las familias (alcanzables) de la base de datos [típicamente unas 500-600 familias para cada periodo de tiempo]. Las medidas de centralidad de esas familias fueron dispuestas en funciones de distribución cumulativa normalizadas o según una "curva Lorenz" (que no se presenta aquí) y se calculó el índice Gini global. El índice Gini es una medida estandar de desigualdad. (Literalmente, es el porcentaje del área bajo una línea de $45^{\circ}$ por encima [o por debajo, depende de la orientación] de la cual se pliega la curva Lorenz empírica).

Los resultados se presentan en la Figura 2. Se aprecian diferencias más claras tanto a lo largo del tiempo como en cada medida. El primer punto a notar es que los números absolutos son muy elevados, indicando que la élite florentina estaba muy concentrada / centralizada - un hecho que ya sabíamos más o menos. Por supuesto parte de esta concentración era debida únicamente a tamaños de familias sesgados. En Florencia, esto no era en principio una cuestión de variación aleatoria en las tasas de nacimientos. Para un clan, tener un apellido de por sí era una afirmación de estatus - indicaba una preocupación por el patrilineaje, la historia familiar y el honor. Unos $2 / 3$ de las personas en la sociedad tenían nombres como 
REDES- Revista hispana para el análisis de redes sociales

Vol.21,\#3, Diciembre 2011

http://revista-redes.rediris.es

"Peter, hijo de Paul". Por lo tanto, la variación en el tamaño de las familias no es una variable aleatoria que debe ser controlada, la concentración de hogares en patrilineajes es, de por sí, un mecanismo importante para la concentración de las élites en su conjunto.

\section{ELITE CONCENTRATION/CENTRALIZATION:}

GINI MEASURES OF INEQUALITY IN DEGREE $\&$ BETWEENNESS CENTRALITY

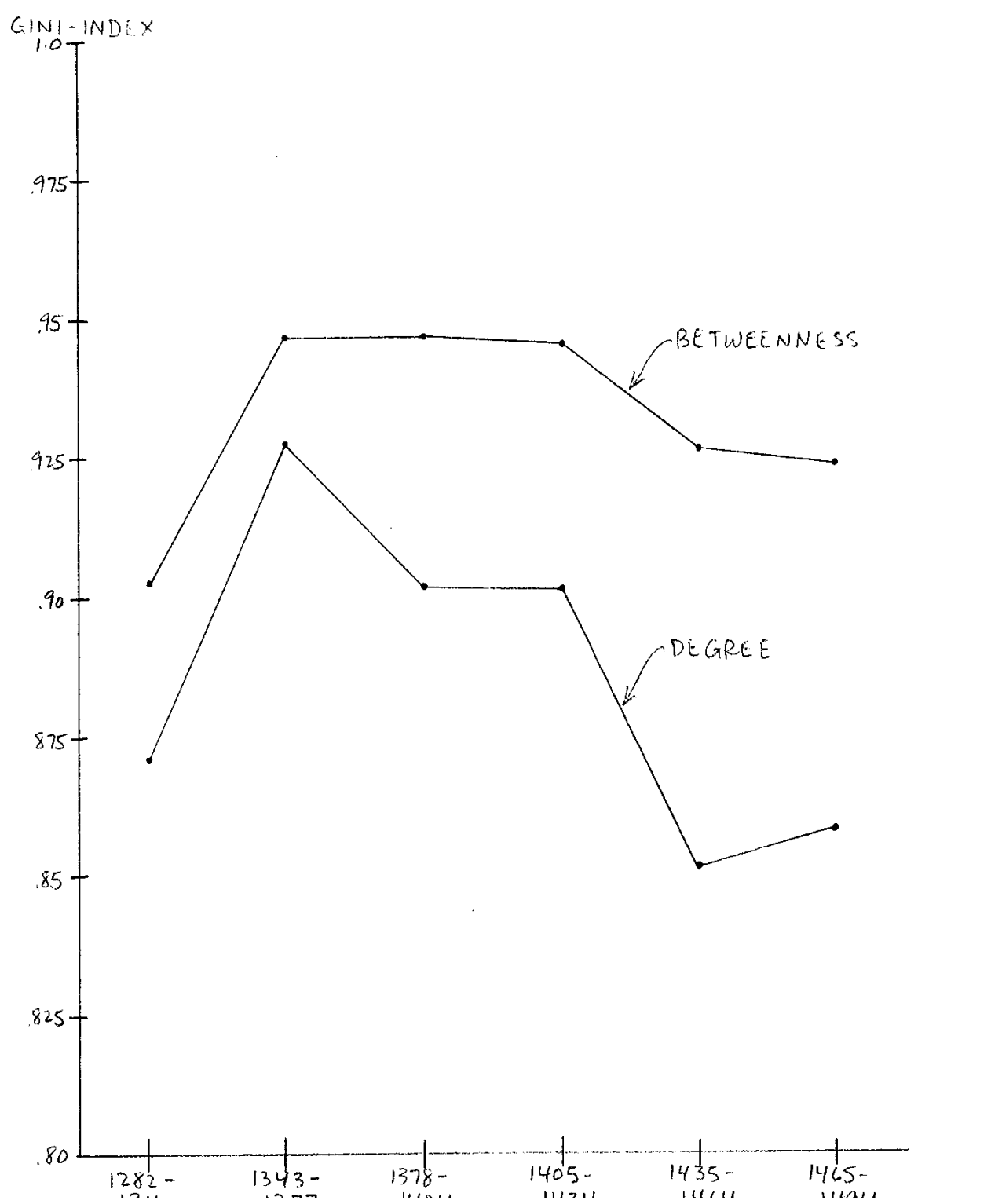

Figura 2. Concentración - centralización de la elite. 
REDES- Revista hispana para el análisis de redes sociales

Vol.21,\#3, Diciembre 2011

http://revista-redes.rediris.es

El índice Gini del "grado" mide cuánto cambia el tamaño de la familia a lo largo del tiempo. Nótese el gran crecimiento en la concentración de la élite de 1282-1342 a 1343-1377. La Muerte Negra de 1348 (y de 1360) representa un candidato obvio para la explicación, aunque la relación precisa entre la plaga y la concentración del tamaño de las familias todavía no me parece obvio. Pero también, el tumulto político de 1343 es una explicación posible. Cualquiera que fuese el motivo, está claro que la concentración de "intermediación" traza exactamente la del grado. En otras palabras, hubo un aumento dramático de la concentración estructural de la élite alrededor de 1343 o 1348, debido a dinámicas patrilineales subyacentes.

Desde 13431348 en adelante, hubo un declive en la concentración de los tamaños famliares. Esto era debido a la vez al declive de los clanes de Magnates realmente grandes, como los Bardi o los Buondelmonti, y al número crecientes de los hogares de la clase media que asumieron apellidos. (El porcentaje de la población con apellidos aumentó de $1 / 4$ a $1 / 2$ a lo largo de esta longue durée). Excepto un descenso modesto del periodo de la república (1343-1434) al periodo de los Medici (14351494), este declive de la concentración del tamaño/grado de las familias no fue correspondido con un declive paralelo en la concentración "estructural" o de intermediación. En otras palabras, una vez ubicada por los acontecimientos de 1343 o 1348, la concentración de la red de la élite se mantuvo por si misma a pesar de las grandes presiones demográficas en sentido opuesto.

La brecha entre la curva del grado y la de la intermediación, en efecto, puede ser tomada como una medida de las presiones de la red de inter-matrimonios hacia la concentración de la élite, limpio de la dinámica de patrilineaje del tamaño de las familias. Esta presión que centraliza la red aumenta con el tiempo, con cambios notables en la función inmediatamente después de la rebelión Ciompi (1378) y después del comienzo del régimen Medici (1434). A pesar de la presión aumentada bajo los Medici para la concentración de la élite, las fuerzas demográficas no fueron totalmente contrarrestadas. 
REDES- Revista hispana para el análisis de redes sociales

Vol.21,\#3, Diciembre 2011

http://revista-redes.rediris.es

\section{Díadas y tríadas}

Se puede tener una mayor comprensión del carácter de la transformación de estas élites al examinar el censo de las díadas y las tríadas - es decir las distribuciones de las micro-relaciones subyacentes al retrato global de la figura 2. Dos características de interés común a los analistas de redes sociales son la asimetría y la transitividad.

La asimetría - es decir la prevalencia de relaciones que van en una única dirección $(\rightrightarrows)$, relativamente a relaciones que van en ambas direcciones $(\leftrightarrows)$ - es comúnmente interpretada como un indicador de micro preocupación por la jerarquía. Aquí, estamos hablando de relaciones de matrimonio; por lo tanto, la asimetría significa que sólo un clan envía hijas o hijos a otro clan (más probable que de forma aleatoria). La simetría, por otra parte, quiere decir que se componen alianzas a través del intercambio de hijos sin tener en cuenta el género. La asimetría en las redes aparece porque la direccionalidad del flujo tiene un sentido cultural para los participantes - habitualmente connota un estatus relativo. [La asimetría, tal y como está medida aquí, sin embargo, no diferencia entre las hijas y los hijos; sólo el flujo exclusivo en una dirección de un flujo simétrico indiferenciado].

La Figura 3 representa la asimetría observada a lo largo del tiempo. Antes de 1343, había una micro preocupación extremadamente fuerte con el estatus relativo [asumiendo que esto sea lo que la asimetría en el matrimonio signifique culturalmente - una suposición que será investigada más a fondo en el futuro]. Pero en los años de la plaga de 1348, o alrededores, esta preocupación diádica entre matrimonios con estatus relativo desaparece inmediatamente. A lo largo del tiempo, gradualmente se reorganiza a si misma - volviendo finalmente a los niveles anteriores a 1343 al llegar al periodo de Lorenzo de' Medici (1465-1494).

En la superficie, los microdatos sobre las díadas asimétricas en la Figura 3a parecen directamente contradictorios respecto a los datos macro sobre la concentración global de la red en la figura 2. Las tendencias de "jerarquía" se están moviendo en direcciones opuestas. Esta aparente contradicción será (parcialmente) resuelta más abajo, después de que hayamos reunido más claves.

La Figura 3b presenta las tendencias en la transitividad - es decir, el porcentaje de tríadas transitivas respecto a los ciclos. La transitividad, por supuesto, no es por sí misma una medida de preocupación micro con la asimetría; es una medida de consistencia de la agregación de las díadas asimétricas a lo largo de múltiples familias. Las díadas asimétricas bajo condiciones de transitividad se agregan juntas 
REDES- Revista hispana para el análisis de redes sociales

Vol.21,\#3, Diciembre 2011

http://revista-redes.rediris.es

en órdenes jerárquicos (pecking order) auto-consistentes; las tríadas intransitivas (o "ciclos") inhiben incluso las díadas jerárquicas de una organización en rangos. Por el contrario, los ciclos inducen el cierre de las fronteras de los grupos, con una jerarquía revuelta dentro del grupo.

DYAD: TRIAD ANALYSIS (pantial)

Dyod Asymanetry:
$\eta_{0} \rightrightarrows$ vs $\leftrightarrow$ :

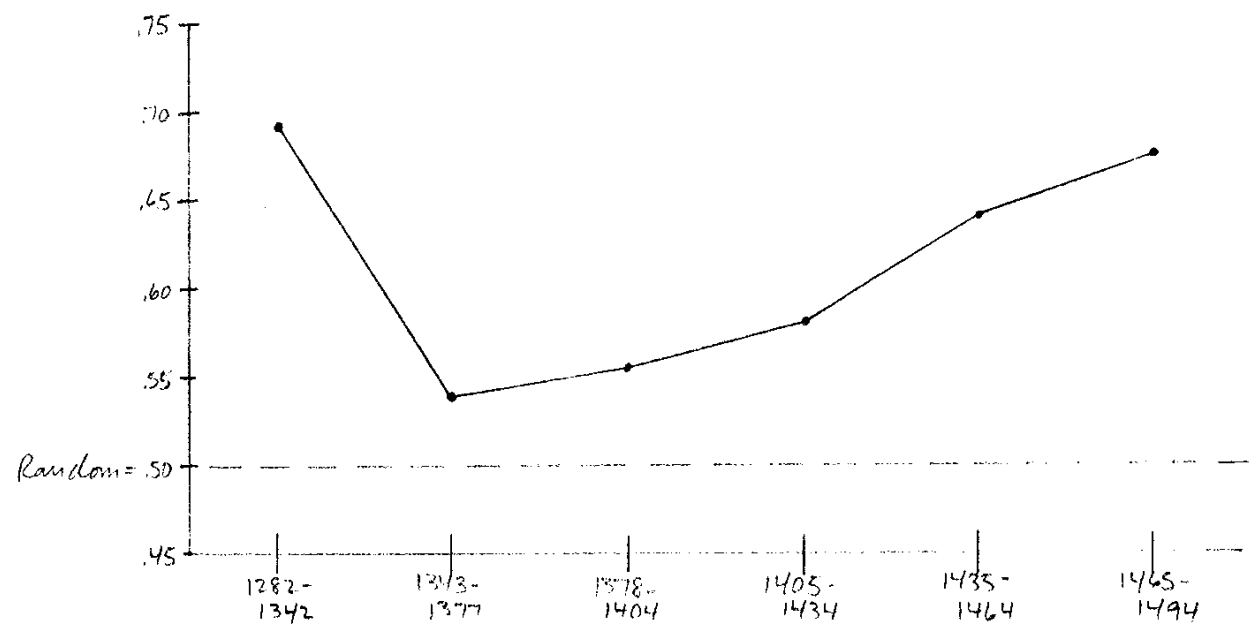

Triad Transitivity:

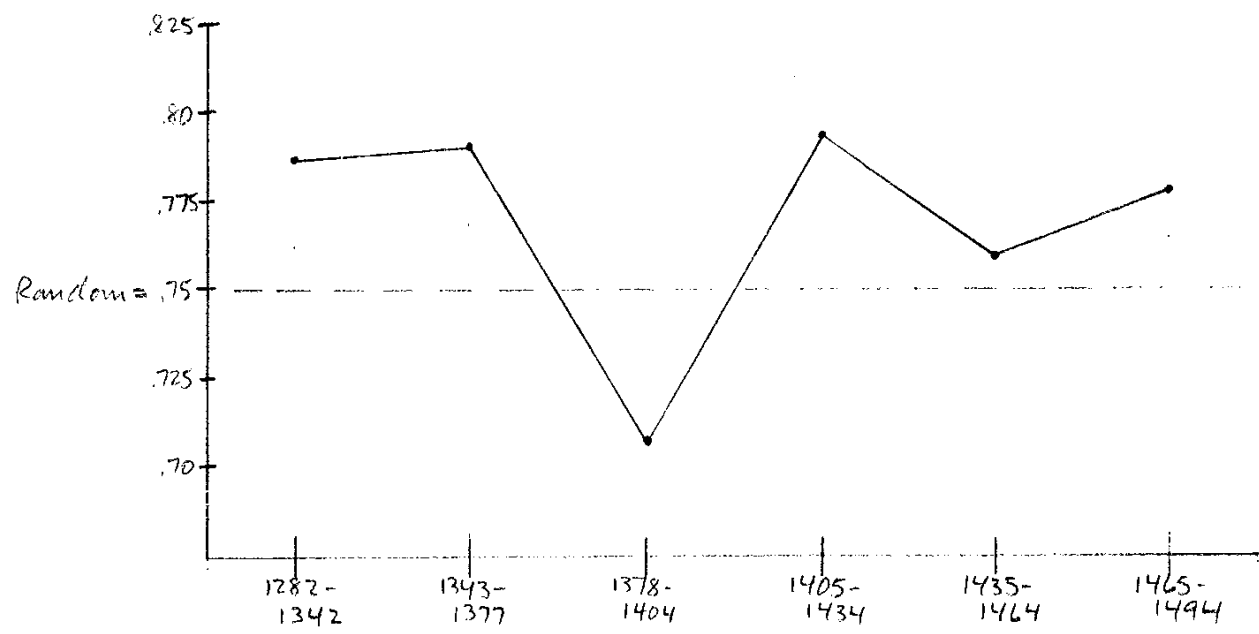


REDES- Revista hispana para el análisis de redes sociales

Vol.21,\#3, Diciembre 2011

http://revista-redes.rediris.es

2-Dyad Amaleses of Symmetry $(\rightleftarrows)$ vs. Asymmetry $\Leftrightarrow)$

A) NEIGHBORHOOD ENDOGAMY:

\begin{tabular}{|c|c|c|c|}
\hline & \multicolumn{3}{|l|}{ All: } \\
\hline & $\begin{array}{c}\% \\
\text { LSYMMETRKK }\end{array}$ & $\begin{array}{l}\text { Im-Quarta: } \\
\text { O. AsymmesRre }\end{array}$ & 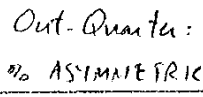 \\
\hline $1282-1342$ & .692 & $20 / 30=.667$ & $34 / 48=.708$ \\
\hline $1343-1377$ & .540 & $50 / 78=.641$ & $82 / 164=.500$ \\
\hline $1378-1404$ & 556 & $22 / 40=.550$ & $36 / 66=.545$ \\
\hline $1405-1434$ & .580 & $10 / 22=.455$ & $48 / 78=.615$ \\
\hline $1435-1464$ & 642 & $30 / 56=.536$ & $92 / 132=.697$ \\
\hline $1465-1494$ & .676 & $38 / 50=.760$ & $106 / 166=.639$ \\
\hline
\end{tabular}

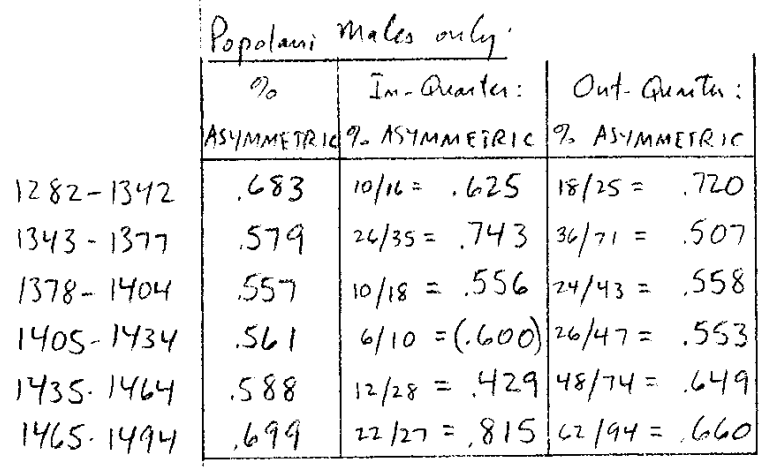

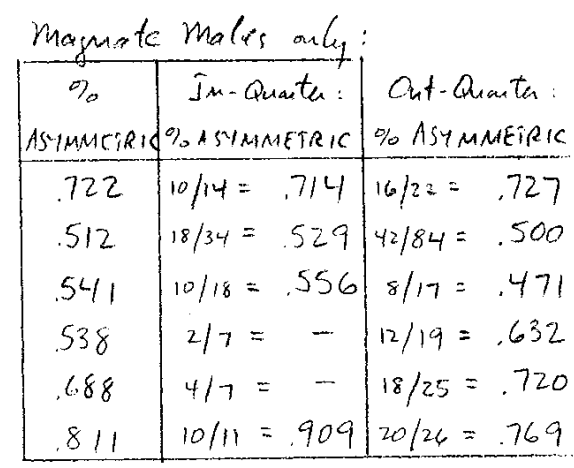

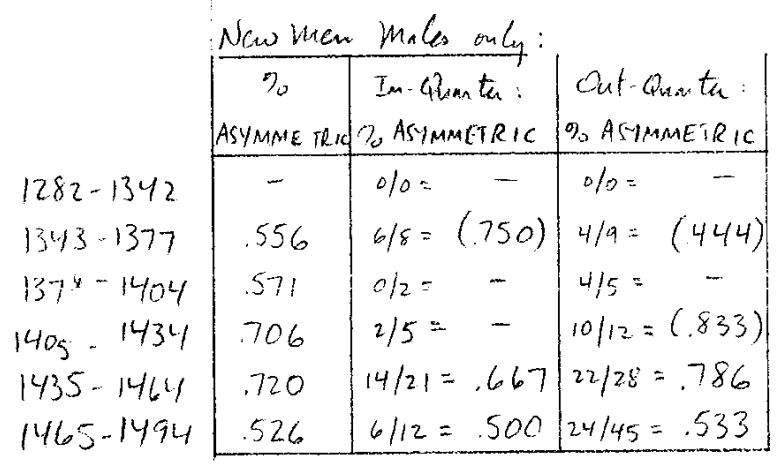

Figura 3 (a y b). Análisis de las díadas y las tríadas.

En conjunto, hay una tendencia notable hacia la transitividad, aunque no es tan llamativa como lo había anticipado. Las tendencias jerárquicas entre dos familias, en otras palabras, siendo habitualmente reforzadas, no socavadas, por los matrimonios de esas dos familias con terceras familias exteriores. Sin embargo, la élite florentina fue rara vez monolítica o estrechamente estructurada. Las 
REDES- Revista hispana para el análisis de redes sociales

Vol.21,\#3, Diciembre 2011

http://revista-redes.rediris.es

inconsistencias, contradicciones, y (aparentes) confusiones en la estructura de la red eran rampantes. Por ello, siempre había espacio estructural para maniobrar y aumentar o disminuir los órdenes jerárquicos (algo que la turbulencia de la historia económica y política florentina nos debería haber conducido a esperar).

La única excepción evidente de esta tendencia (débil) de conjunto hacia la transitividad es el periodo 1378-1404, que exibe una tendencia por encima de la esperada hacia los ciclos. En mi artículo de 1993 ofrecía una explicación de las causas en la rebelión Ciompi de estos ciclos de matrimonio inusuales, y de las consecuencias de la cooptación política de estos ciclos específicos a ciertos periodos. Naturalmente me complace ver (algunas de) mis primeras hipótesis confirmadas por datos más extensos.

\section{Endogamia residencial}

La figura 4 presenta las tendencias en la endogamia residencial - es decir, la velocidad con la que las familias de las élites florentinas se casaban con sus "vecinos" definidos como co-residentes dentro de los cuatro barrios de Florencia (Santo Spirito, Santa Croce, Santa Maria Novella, y San Giovanni). Estas tendencias residenciales son subdivididas más allá por clases sociales - (a) Magnates, aquellas familias antiguas y prestigiosas legalmente excluidas del funcionariado plublico; (b) popolani, aquellos viejas (anteriores a 1343) familias que participaban en el gobierno florentino; (c) los "hombres nuevos", aquellos participantes en el gobierno florentino cuyas familias fueron admitidas en el priorato sólo después de 1343.

En general los datos en la figura 4 confirman lo que ya se sabe - que la importancia de la endogamia residencial dentro de la élite florentina decreció con el tiempo. [Entre los popolo-minuto más bajos aumentó]. Lo que es nuevo aquí es la temporalidad y la composición de clase.

Entre las familias popolani, la endogamia residencial comenzó con un nivel inicial muy alto $-45 \%$ en el matrimonio durante 1282-1314. A lo largo del siglo catorce, sin embargo, continuó decreciendo, hasta que, en el siglo quince, el vecindario se volvió irrelevante para el matrimonio. Los popolani del siglo quince estaban muy mezclados y eran residencialmente homogéneos. Las familias de Magnates experimentaron un declive agudo y precipitado en el matrimonio intra- barrio muy temprano en el tiempo - de 1282-1314 a 1315-1342. Después de ello, las diferencias residenciales entre las clases de Magnates eran irrelevantes. 
REDES- Revista hispana para el análisis de redes sociales

Vol.21,\#3, Diciembre 2011

http://revista-redes.rediris.es

RESIDENTIAL

MARRIAGE ENDOGAMY:

\%。 In-Quarter

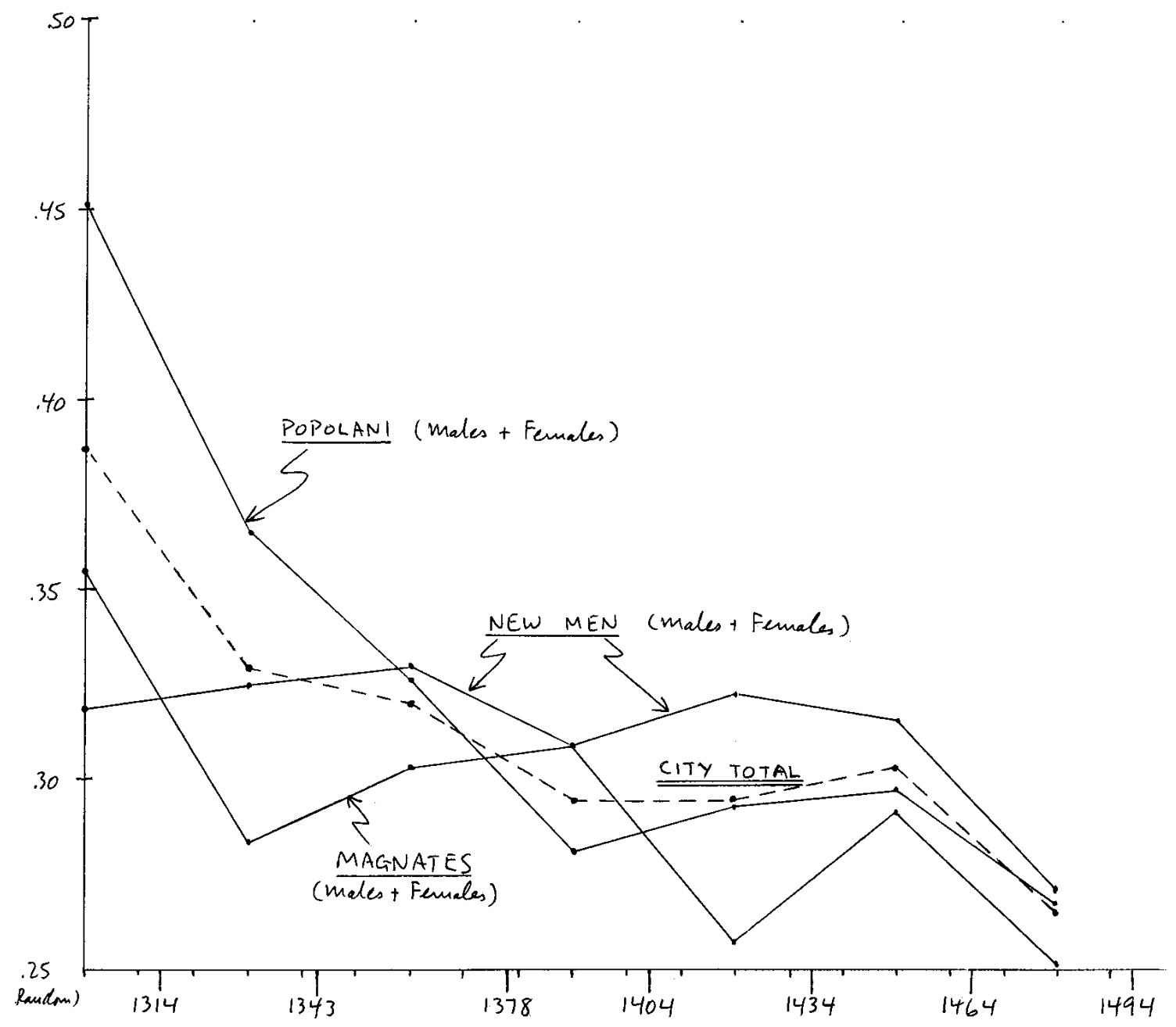

Figura 4. Tendencias en la endogamia residencial.

Contrastando con estas dos tendencias, que difieren en su temporalidad y magnitud, pero no en su modelo, los "hombres nuevos" no experimentaron esencialmente ningún cambio a lo largo del tiempo [hasta que, de forma discutible, en el periodo Lorenzo los tres grupos declinaron aún más de niveles que ya eran bajos - un fenómeno a estudiar en el futuro]. Por este motivo, interpreto a los 
REDES- Revista hispana para el análisis de redes sociales

Vol.21,\#3, Diciembre 2011

http://revista-redes.rediris.es

"hombres nuevos" como un grupo de control. Esto me permite decir que aproximadamente el $32 \%$ de todas las familias florentinas se casarían con vecinos del barrio por motivos exclusivos de cercanía, sin ningún otro tipo de consideración. [Por lo tanto la cercanía física aumenta la línea de base nula de su nivel meramente al azar de $25 \%]$. Por lo tanto, entre los popolani y los magnati, tanto los niveles de endogamia residencial del alto siglo catorce (especialmente pre-1343) como los bajos niveles de endogamia del bajo siglo quince (que comienzan después de 1378) son fenómenos sustantivos importantes que requieren una explicación histórica.

Una buena parte de mi artículo de 1993 se dedica a explicar el declive post Ciompi de la endogamia residencial popolani. Pero los datos aquí sugieren una modificación importante en la parte de mi argumento anterior que concierne el periodo anterior a 1378. Había sugerido que una base de la estructura "medieval" de los matrimonios cruzados podía ser caracterizada (en una forma idealizada) como la federación de las jerarquíaas de los matrimonios basados en el vecindario. Es decir, que las familias de "barones" locales en competición organizaban a sus seguidores vecinos-patricios a través de matrimonios hipógamos asimétricos, pero se relacionaban entre ellos sólo finamente en la cúpula con unos pocos matrimonios de élite entre vecinos. En otras palabras, dentro de la élite, se obtiene una gran concentración jerárquica de matrimonios entre vecinos, pero sólo una concentración débil en la ciudad en su conjunto.

Las figuras 2 a 4 son totalmente consistentes con este retrato, pero sólo para el periodo anterior a 1343 (no 1378, como yo suponía). [En mi defensa diré que había insertado una nota de advertencia en el texto sobre posibles variaciones caprichosas en el tiempo]. Todas las figuras indican una transformación extremadamente importante que interviene en la estructura de la élite florentina en los alrededores de 1343 o 1348, cuya existencia no conocía antes. Las fases futuras de la investigación demostraran más estas cuestiones importantes.

\section{Endogamia de clase social}

La figura 5 (tres partes) presenta las frecuencias de los matrimonios entre clases sociales a lo largo del tiempo. El panel 5a presenta las frecuencias de los matrimonios entre hombres popolani y mujeres popolani, Magnates y "hombres nuevos". El Panel 5b hace lo mismo para los hombres magnate y el panel 5c hace lo mismo con los hombres "hombres nuevos". La línea gruesa de todos estos grafos corresponde a las frecuencias empíricamente observadas; las líneas más finas son las frecuencias estadísticamente esperadas, basadas únicamente en los números relativos de matrimonios en cada una de estas categorías. Los asteriscos indican las 
REDES- Revista hispana para el análisis de redes sociales

Vol.21,\#3, Diciembre 2011

http://revista-redes.rediris.es

diferencias estadísticamente significativas entre las frecuencias esperadas y las observadas, basadas en los test chi-cuadrado (que no se indican aquí). En este punto, es importante tener en cuenta las frecuencias estadísticamente esperadas para la interpretación, dado que las familias Magnates decrecieron dramaticamente en tamaño y número (e importancia) a lo largo del tiempo mientras que las familias de "hombres nuevos" hicieron lo contrario. [Recuérdese la observación anterior sobre la evolución del grado a lo largo del tiempo].

Social Inta-Class marniage Rates (8/94)
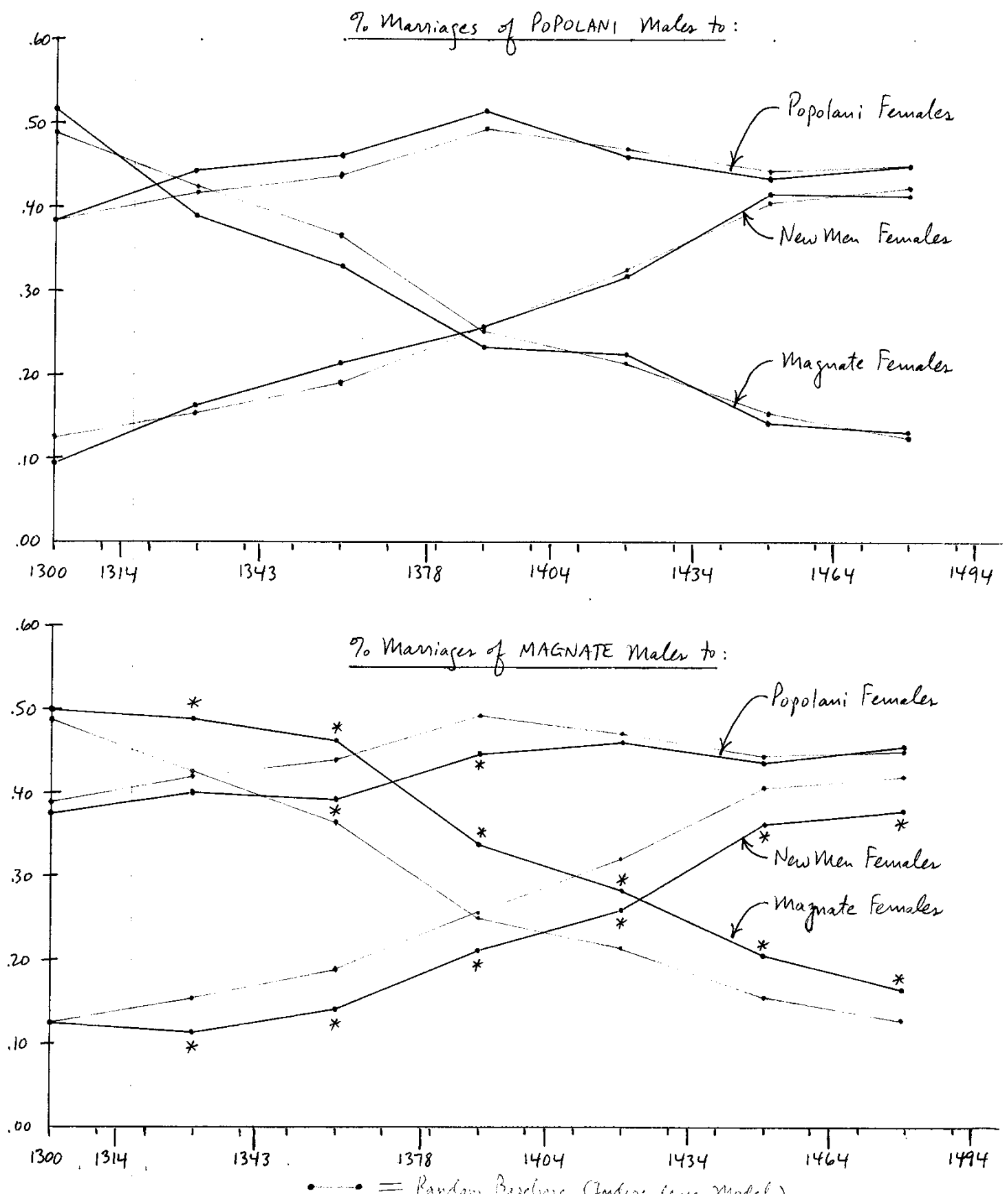
REDES- Revista hispana para el análisis de redes sociales

Vol.21,\#3, Diciembre 2011

http://revista-redes.rediris.es

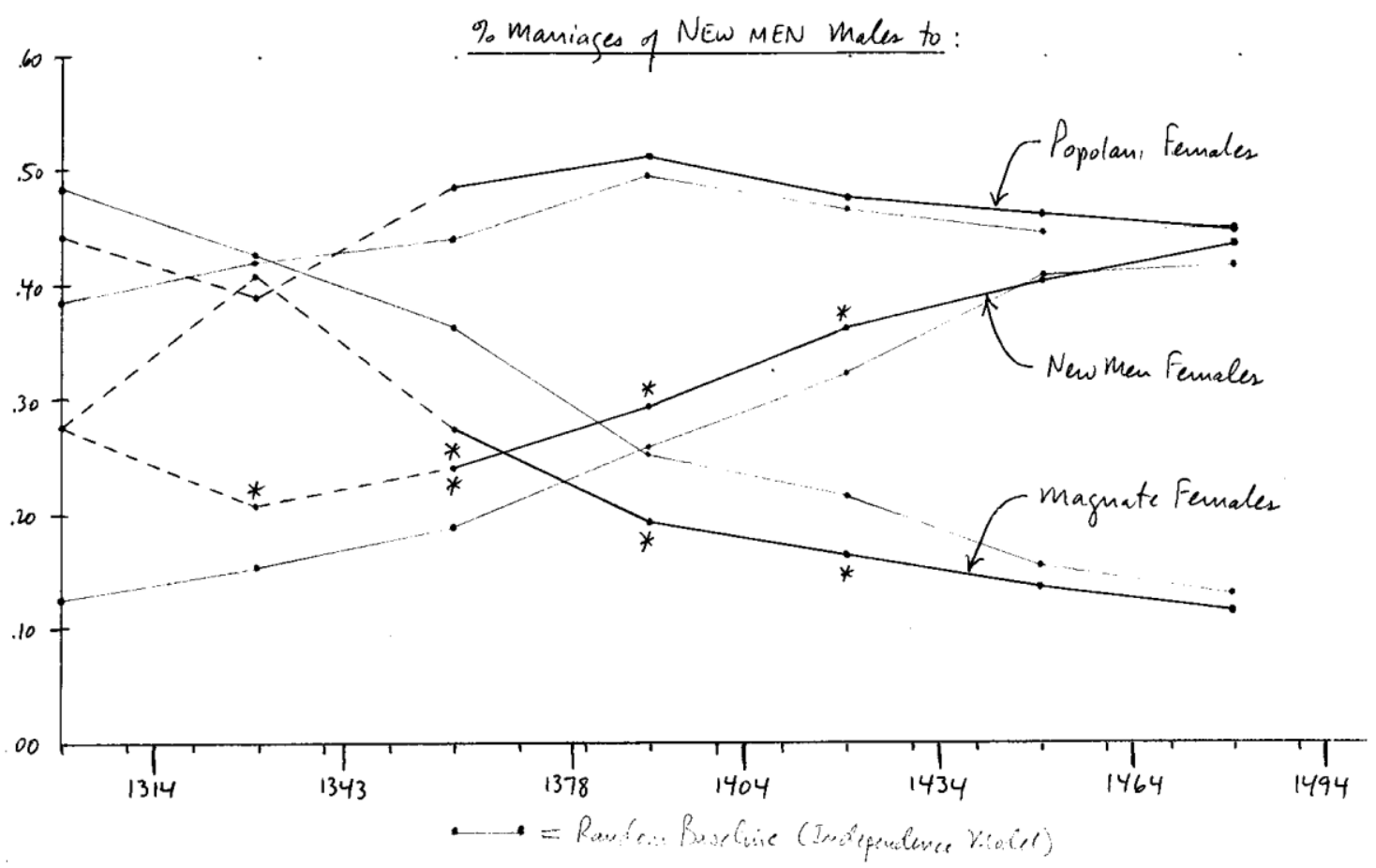

Figura 5 (a, b y c). Frecuencias de los matrimonios entre clases sociales a lo largo del tiempo.

Tal vez el hallazgo más sorprendente en todos estos grafos es el hecho de que las familias popolani se casaban con otras clases sociales con una frecuencia igual a la que hubiera sido esperada estadísticamente al azar (es decir dependiendo únicamente de los tamaños relativos). Los Magnates, los popolani y los "hombres nuevos": tales etiquetas de clases sociales no importaban nada para los comportamientos de los matrimonios popolani. Las familias popolani eran sorprendentemente caóticas en su manera de escojer con quién se casaban.

Las familias popolani, recordemos, eran las familias más poderosas de Florencia. Como conjunto de familias individuales, dominaron claramente Florencia durante siglos. Los datos aquí, sin embargo, no dejan una sombra de ambiguedad: como grupo de comportamiento, al menos tal y como se expresa en los matrimonios cruzados, los popolani sencillamente no existían. Los popolanis se mantenían en la intersección del prestigio social y el poder politico, pero la multiplicidad de sus bases de dominación aparentemente condujeron a la disolución, y no la confirmación, de su identidad de grupo. Cualquiera que fuese la opinión de los demás sobre ellos, pensaban continuamente en sí mismos únicamente como "ciudadanos públicos de Florencia" - es decir, como un conjunto de familias 
REDES- Revista hispana para el análisis de redes sociales

Vol.21,\#3, Diciembre 2011

http://revista-redes.rediris.es

individuales con un derecho natural de gobernar, pero no como un grupo dominante con una auto-conciencia corporativa especial. [Reconozco que esta conclusión se extrapola un poco de los datos - un error a corregir en borradores futuros]. Tal vez éste es un corolario de la "hegemonía": la identidad de grupo es una preocupación para las personas que no tienen el poder, pero no para los que lo tienen. [Esto es consistente con lo que argumenté, para un período más limitado del tiempo, en mi artículo anterior].

Esta interpretación se refuerza por el hecho de que las familias de los Magnates se volvieron marcadamente endógamas como grupo precisamente en el momento en que perdieron cualquier posibilidad de reclamar el poder. Habían sido excluidos inicialmente en los años 1290, pero aún así lucharon dentro del sistema hasta su última tentativa de volver, con un golpe, que falló, en 1343. Antes de 1314, los datos muestran que los Magnates tienen el mismo comportamiento que los popolani - a pesar de las sanciones legales, se casaron temporalmente con popolani y con "hombres nuevos" tan libremente como los popolani. Entre 1315 y 1343, sin embargo, apareció el comportamiento endógamo de los Magnates, que quedaron encerrados "para siempre" por los acontecimientos de 1343, incluso cuando sus fortunas colectivas ( $y$ número) se hundieron gradualmente bajo el horizonte a partir de entonces.

Los datos son más específicos en ésto. La endogamia magnate fue lograda principalmente a costa de unas frecuencias de matriminoio más bajas con los "hombres nuevos" no con los popolani. Aunque es cierto que los hombres Magnates se resistieron a casarse con mujeres popolani de 1343 a 1400 (más o menos), antes de 1343 y después de 1400 los Magnates no discriminaban a los popolani (quienes, como hemos visto, en ningún momento los habían discriminado). La antipatía mutua era realmente entre los Magnates y los "hombres nuevos". [Este hallazgo estadístico es muy consistente con los relatos narrativos].

Por el contrario, la endogamia entre "hombres nuevos", en la medida en que las cifras nos permiten observarlo con confianza (es decir después de 1343), fue obtenida exclusivamente a costa de matrimonios menos frecuentes con los Magnates. Las familias de "hombres nuevos" nunca discriminaron a los popolani, ni tan sólo de forma temporal. [Para los "hombres nuevos", esto no es una sorpresa los popolani eran precisamente el club al que los "hombres nuevos" querían unirse. La sorpresa es la contraria - que los popolani no discriminasen a los "hombres nuevos"]. Hasta el regimen de los Médici (post 1434) los "hombres nuevos" no renunciaron a su antipatía por los Magnates. En ese punto había sido retirada la 
REDES- Revista hispana para el análisis de redes sociales

Vol.21,\#3, Diciembre 2011

http://revista-redes.rediris.es

prohibición oficial del servicio publico; tal vez para entonces los Magnates ya no consituían una amenaza. Es interesante obsevar sin embargo que, incluso en una fecha tan tardía, los Magnates mismos continuaban manteniendo rencor contra los "hombres nuevos" (no contra los popolani), quienes les habían sobrepasado ampliamente en número y poder. Los antiguos recuerdos de los aristocratas en declive se resisten a morir.

\section{Endogamia de riqueza e hipogamia}

También está la cuestión de la definición de la endogamia y la (posible) hipogamia, no tanto entre las clases sociales, sino entre las clases económicas - es decir respecto a la riqueza. Ésta es una cuestión espinosa sobre la que ha habido mucha controversia recientemente entre Anthony Molho y el David Herlihy tardío.

En las secciones anteriores no discutí (la enorme cantidad de) las bases detalladas de las investigaciones, de las fuentes de datos y codificación, de la gestión y relación de los datos y de los algoritmos de los ordenadores - porque al menos tengo confianza en mi capacidad de respaldar esto a su debido tiempo. [Por supuesto, todo esto será explicado en una publicación a gran escala]. En el caso de la cuestión de la riqueza a lo largo de dos siglos, sin embargo, es necesario discutir algunas dificultades practicas, para subrayar la naturaleza tentativa $* * *$, no definitiva, de las siguientes conclusiones.

Como se mencionó en la sección de los datos, tengo evaluaciones de impuestos sobre la riqueza a nivel de todos los hogares con apellidos para 1351, 1378 y 1427. [Los dos primeros codificados por mí; el de 1427 codificado por Herlihy y Klapisch]. Para 1403, 1458 y 1480, sin embargo, tengo actualmente sólo enumeraciones parciales - los 500 hogares más ricos en los tres años (cortesía de los apendices en Martines y en Molho), y una muestra de $10 \%$ para 1458 y 1480 (cortesía de Herlihy y Klapsich de Nuevo). Esto significa que si quiero realizar afirmacioness que cubran el período de tiempo entero, debo agregar a nivel del clan total - es decir, debo sumar la riqueza de todos los hogares con apellidos communes (añadiendo los hogares sin apellido cuando sé que forman parte de los miembros del clan). Naturalmente esto no cubre la mayoría de los miembros (desconocidos) pobres de los clanes en 1403, 1458 y 1480, pero defiendo que de todos modos sirve para recrear (aproximadamente) de forma razonable la jerarquía de rangos de los 960 clanes en mi base de datos. La riqueza media de los hogares por clan puede ser estimada (de nuevo aproximadamente) dividiendo la riqueza total del clan por el número de hogares por clan, conocida exactamente para 1351, 1378 y 1427; y estimada para otros años, bien mediante extrapolación para 1351, 1378 y 1427 o 
REDES- Revista hispana para el análisis de redes sociales

Vol.21,\#3, Diciembre 2011

http://revista-redes.rediris.es

mediante estimación de los números de matrimonios en mi base de datos. [EI último método para estimar el tamaño de los clanes es más preciso, pero aquí me limito al primer método (más facil)].
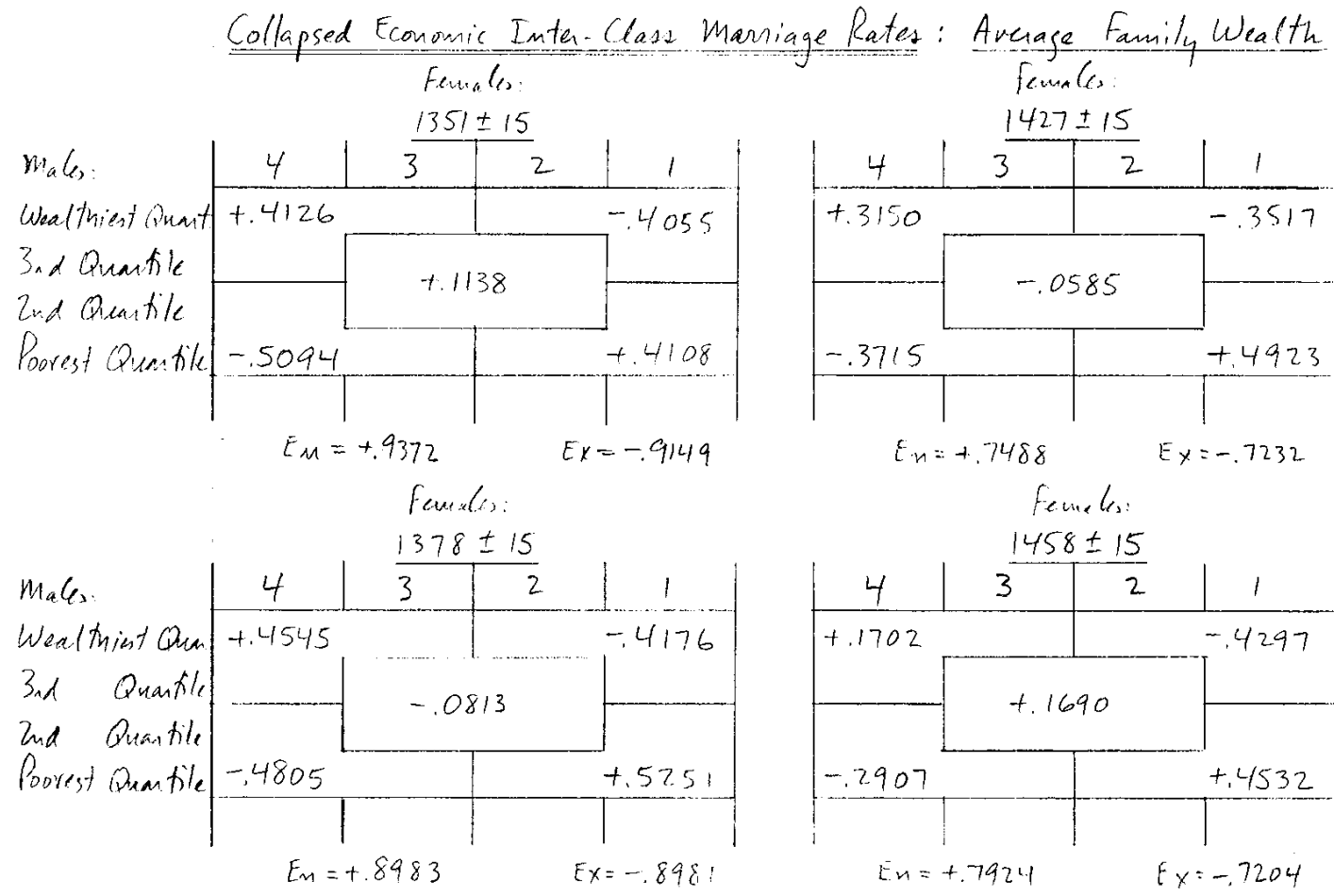

remale.

Fandes:

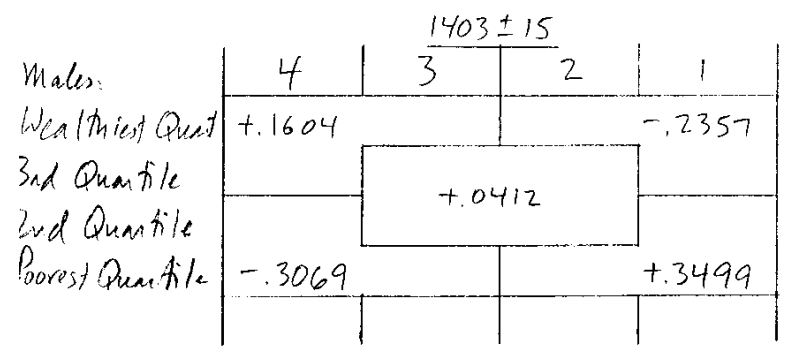

$E_{n}=+.5515 \quad E_{x}=-.5426$

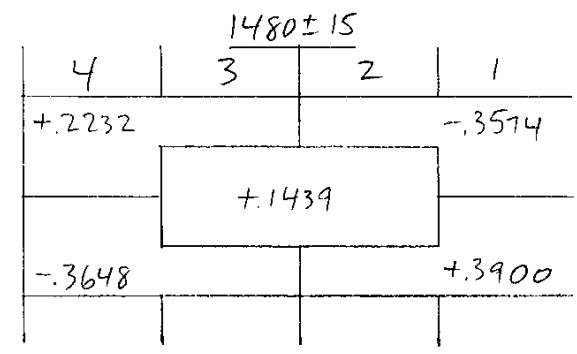

$E_{n}=+.7571$

$t y=-.7222$

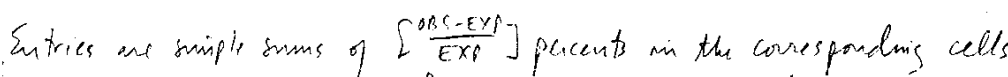

8 the giell tobles. (Punpose "jest of visealijing pattern)

Tabla 1. Endogamia de las familias acomodadas. 
REDES- Revista hispana para el análisis de redes sociales

Vol.21,\#3, Diciembre 2011

http://revista-redes.rediris.es

Realizar el análisis completo al nivel de agregación de los hogares eliminaría muchos errores potenciales, ciertamente, pero actualmente (todavía) no puedo hacerlo.

A pesar de las advertencias, los resultados (aproximados) sobre la endogamia de riqueza se presentan en la tabla 1 . A causa de los temas recién discutidos, sólo me fijé en los cuartiles de riqueza, tratando, por lo tanto, únicamente como significativas las grandes diferencias en la riqueza media medida. Además reagrupé las 16 casillas de las tablas de $4 \times 4$ a 5 casillas, de acuerdo con el esquema mostrado en la tabla 1, para suavizar las fluctuaciones obvias de ruidos (que presumiblemente no aparecerían con datos más limpios).

En las seis subtablas, una para cada período, los datos se distribuyen en funciones de silla de montar. Es decir, para cada período, los ricos eran endógamos; los pobres eran (aún más) endógamos; pero las clases medias no lo eran. Además (sin que sea una sorpresa), los ricos no se casaban con los pobres y a la inversa.

La hipogamia es un modelo de casamiento cruzado en que es más probable que todos (pero especialmente las clases altas) envíen hijas hacia abajo de la escala social, en lugar de enviarlas hacia arriba. No hay evidencias de hipogamia en ninguna de estas tablas de riqueza. (Tampoco había evidencias de hipogamia entre las clases sociales, definidas de forma no económica a partir de la "fecha del primer prior"). Para ser justo con Herlihy, estos análisis no tienen en cuenta todavía el impacto que la dote tenía en la riqueza - una cuestión que él consideraba crucial en la medida de la hipogamia - y por lo tanto debe ser considerada sólo como provisional. Pero hasta ahora los datos apoyan la posición de Molho - es decir, que los matrimonios de la élite (de los ricos) florentina era a la vez endógama y homógama.

De forma consistente con Cohn, pero no enfatizada con Molho, también está el hecho de que los pobres eran aún más endógamos que los ricos. De hecho, los comportamientos de matrimonios endógamos (y homógamos) de los ricos y los pobres en Florencia pueden no ser fenómenos independientes - la aversión mutua puede haber conducido a la endogamia mutua.

El grado cuantitativo de esta característica, por otra parte, constante en la sociedad florentina, parece, sin embargo, haber cambiado algo a lo largo del tiempo. Dejando a parte la tabla aberrante de 1388-1418 (que contiene los datos más sucios), el siglo XIV [es decir, tanto las tablas de 1336-1366 como las de 13631393] mostraban una endogamia de riqueza más intensa ( $y$ aversión mutua) que en el siglo XV [es decir las tablas 1402-1442, 1443-1473 y 1465-1495]. Esto se 
REDES- Revista hispana para el análisis de redes sociales

Vol.21,\#3, Diciembre 2011

http://revista-redes.rediris.es

indica en las estadísticas "En=" y "Ex=" debajo de cada tabla, lo que simplemente añade las céldas noreste y sureste y las celdas noroeste y sureste respectivamente. [Dichas sumas miden las "pendientes" de la función en forma de silla de montar]. Estas estadísticas, siempre elevadas, son particularmente pronunciadas en los dos periodos de tiempo más tempranos. Esta tendencia temporal me resulta antiintuitiva (probablemente a Molho también); de momento no sé cómo explicarla.

Una tensión no resuelta entre los análisis de más arriba es que la figura 3a de díadas de matrimonios asimétricos muestra una variación histórica clara a lo largo del tiempo, mientras que, aparentemente, ni la hipogamia ni la hipergamia existían - al menos no respecto a la riqueza o la clase social. Dicho de otro modo, era manifiesta una preocupación aguda por las díadas con una jerarquía relativa entre asociados que intercambian matrimonios, tanto al principio como al final del Renacimiento. Pero esto no estaba basado (aparentemente) en los critrios atributivos habituales. Dichas jerarquías relativas estaban basadas en otro tema importante para investigaciones futuras.

\section{Escalado multidimensional de distancias de los caminos}

Finalmente, en un apéndice, presento una serie de gráficos de escalado bidimensional, para cada período del tiempo, de las distancias relativas de matrimonios entre las familias más importantes. (Una "distancia del camino entre familias" aquí es simplemente el número más corto de matrimonios encadenados necesarios para "alcanzar" unas a otras). Cuando se ven como una serie, estos gráficos dan una "imagen móvil" de cómo cambiaba la estructura de la élite a lo largo del tiempo, como se ve con una perspectiva de "ojo de pájaro" mirando abajo hacia la estructura. [De forma contrastada con, por ejemplo, la mirada "lateral" de la centralidad, que mira a la pendiente (cambiante) relativa de la "montaña"].

Había demasiados clanes en el análisis MDS para presentarlo visualmente en una imagen, así que para facilitar la lectura muestro únicamente los 60-70 clanes más grandes (en grado) en el apéndice. Por favor, recuérdese, sin embargo, que los análisis estadísticos subyacentes a estos gráficos espaciales están basados en $500-$ 600 clanes y no sólo en los 60-70 mostrados.

La información contenida en estos diagramas MDS es demasiado rica e impactada para ser absorbida a primera vista. Uno necesita saber mucho sobre quienes son estas familias para ser capaz de interpretarlas. Sin embargo, en lugar de la discusión detallada que sucederá en borradores futuros de este texto, simplemente indicaré algunas cuestiones que destacan. 
REDES- Revista hispana para el análisis de redes sociales

Vol.21,\#3, Diciembre 2011

http://revista-redes.rediris.es

1. Una característica destacable del cambio entre 1282-1342 a 1343-1377 (una transición apuntada antes como muy significativa) es que en 1282-1342 los Magnates estaban distribuidos de forma más o menos homogénea a lo largo de este espacio de familias muy de la élite [aunque con un claro sesgo hacia la izquierda del diagrama] cuando en 1343-1377 los Magnates se movieron fuertemente hacia el centro del espacio. [Nótese el cambio de magnificación la parte baja de la segunda figura]. Después, los Magnates comenzaron a disgregarse espacialmente y entonces, eventualmente, a desaparecer (puesto que ya no formaban parte de las 60-70 familias más importantes). La endogamia de los Magnates, aunque real, fue insuficiente para compensar la enórme pérdida de su número.

Se pueden reunir varios elementos para formar un retrato provisionalmente claro de la misteriosa (al menos para mí) transición en la estructura de los matrimonios en 1343-1377. La figura 2 mostraba una centralización impresionante de la élite florentina en su conjunto en 1343 (más o menos); la figura $3^{a}$ mostraba un declive igualmente dramático en la asimetría dentro de las micro-díadas; y la figura 5b mostraba que la endogamia de los Magnates emergía más o menos al mismo tiempo. Uniendo el gráfico MDS con estas otras claves se ve el efecto paradójico de que en 1343 o 1348 la élite florentina en su conjunto se concentraba a partir del matrimonio precisamente alrededor de ese grupo, los Magnates, que acababa de desalojar políticamente para siempre. La figuras $5 c$ y $5 b$ sugieren un motivo: la concentración estaba producida principalmente por una polarización magnate"hombres nuevos" que separó la parte alta y la baja de la distribución de los matrimonios de élite en su conjunto. La asimetría orientada verticalmente de los lazos se fragmentó conforme el sistema tendía a estratificarse en capas separadas. Los popolani se resistieron a esta tendencia, sin embargo, y más o menos lograron mantener su (algo raída) posición de puentes. Los Magnates se quedaron en el centro porque los popolani les seguían teniendo, individualmente, en alta consideración, aunque los Magnates no lo hicieran de forma recíproca (dado que los popolani se habían unido a los "hombres nuevos" como aliados políticos en 1343).

Por lo tanto, aunque el papel de la plaga no se ha incluido en esta explicación [es difícil que no fuese importante], parece plausible que los eventos políticos que rodean al 1343 son al menos una parte de la historia de la dramática primera transición en la estructura de la élite florentina.

2. Los dos últimos gráficos, que cubren 1435-1465 y 1465-1494 (respectivamente los periodos de los reinos de Cosimo de Medici y Lorenzo de Medici), son 
REDES- Revista hispana para el análisis de redes sociales

Vol.21,\#3, Diciembre 2011

http://revista-redes.rediris.es

extremadamente reveladores de la base cambiante del control de los Medici, en la medida en que éstos se manifestaron a través del matrimonio.

Después de que Cosimo alcanzase el poder en 1434, los Medici continuaron estableciendo matrimonios con antiguas familias prestigiosas, continuando con un modelo que ha sido ampliamente expuesto en mi artículo de 1993. En lugar de este cluster de matrimonios de los Medici moviéndos hacia el centro de la élite social florentina, sin embargo (como ciertamente hicieron los Medici en política) los Medici y sus asociados florentinos en los matrimonios [había también importantes matrimonios extra-florentinos en los Medici] se quedaron a distancia, al margen del resto de la sociedad florentina, igual que antes. Sin embargo, a diferencia del periodo 1378-1420, este distanciamiento de 1435-1464 fue presumiblemente voluntario.

Algunos de los detalles de este cluster de matrimonios de los Medici son de gran importancia historiográfica: dentro de la clique de matrimoios de los Medici se encontraban los Strozzi, una de las familias más fuertemente proscritas en ese período, expulsadas de Florencia por los Medici; los Pazzi, infames conspiradores que más adelante trataron de asesinar a los Medici; y los Pitti, dirigentes del partido republicano anti-Medici que emergió a la muerte de Cosimo en 1466. Entre los más cercanos familiares políticos de los Medici, sólo los Capponi no parecen haber creado problemas serios a los Medici. Pero los Capponi eran considerados como unos de los pocos rivales independientemente poderosos de aquel tiempo, capaces de oponerse autónomamente a la voluntad de Cosimo.

Uno pensaría que una clique de antiguos alborotadores prestigiosos, alejados del centro de la élite florentina, sería un terreno muy poco prometedor sobre el que construir la dominación de los Medici. Y en la medida en que estamos hablando de la clique de matrimonios en sí misma, esto es claramente verdad. Sin embargo, nótese que hay un agujero en el centro del resto de la élite florentina, al igual que alguna distancia entre la clique de matrimonios de los Medici y la de los demás.

Un agujero espacial indica la ausencia de relaciones de matrimonio extremadamente peculiar en el centro muerto de cualquier gráfico de MDS [que después de todo está designado algorítmicamente para tratar de minimizar las distancias de los caminos, una minimización habitualmente llevada a cabo a través de tratar de construir un centro denso]. Además, los partidarios de los Medici anteriores a 1434 y sus oponentes están algo mezclados alrededor de este agujero - bastante opuesto a la situación que prevalecía antes de 1434. 
REDES- Revista hispana para el análisis de redes sociales

Vol.21,\#3, Diciembre 2011

http://revista-redes.rediris.es

El control bajo Cosimo, en otras palabras, parece haberse basado una vez más (de forma diferente pero con la misma lógica que la propuesta en mi artículo de 1993) no en el principo interaccionista de traer a los buenos amigos cerca de ti, sino más bien en el principio estructuralista de crear barreras entre tus oponentes. En este contexto, casarse con otros altamente problemáticos puede no sólo haber sido una manera de tenerlos mejor vigilados, sino también una forma de retirarlos del centro del resto de la acción. Cómo se creó y se mantuvo un agujero estructural en el mismo centro de la élite florentina bajo Cosimo es una cuestión probablemente de importancia profunda, pero todavía no la puedo explicar.

3. Compárese este sistema de matrimonio de Cosimo al de Lorenzo. Los Medici de Lorenzo, como los Medici de Cosimo, estaban en los márgenes de los matrimonios de la élite florentina. Pero ahí acaba la similitud. Ilustrado visualmente por una inversión en su localización espacial al lugar exactamente opuesto al ocupado por los Medici de Cosimo, los Medici de Lorenzo establecieron matrimonios principalmente con aliados políticos - a menudo "hombres nuevos" aliados en concreto. Más interaccionista en su lógica de red, Lorenzo envió relaciones de matrimonio a familias amistosas que ya le habían apoyado por otros motivos. Sin duda esto hizo que su seguidores (especialmente los "hombres nuevos") fuesen aún más leales que antes, pero no le dió capacidad de maniobra en la estructura de la élite florentina en su conjunto. Todo lo contrario tal vez - aisló el partido de los Medici y retiró a los seguidores de Lorenzo de sus posiciones profundamente enraizadas en el resto de Florencia, donde hubieran sido más útiles. Más siniestro para Lorenzo fue el hecho de que el agujero estructural en el centro de la élite de Cosimo desapareció.

Sospecho que Lorenzo se volvió hacia este modelo de matrimonio de tipo "rodéate de amigos" a causa de su encuentro cercano con la muerte durante la conspiración Pazzi. Pero no creo que esta aproximación cortés al matrimonio fuese un mecanismo de control efectivo. Por supuesto estuvieron implicadas en el control otras cosas más allá del matrimonio, pero en la medida en que los Medici no podían controlar la élite florentina en su base constitutiva, debieron emplearse más y más mecanismos formales institucionales, por los que Lorenzo era famoso (o considerado infame). Dichos métodos (el Concilio de los Setenta, etc.) son más visibles y obvios para todos.

El rápido declive del régimen Medici, inmediatamente después de la muerte de Lorenzo es tal vez el testigo de la posible veracidad de los, admitidamente especulativos, comentarios presentados. Se podría decir mucho más sobre estos 
REDES- Revista hispana para el análisis de redes sociales

Vol.21,\#3, Diciembre 2011

http://revista-redes.rediris.es

análisis espaciales, especialmente sobre los dos graficos intermedios de 1378-1404 y 1405-1434. Pero el período de 1378-1434 fue examinado ampliamente en mi artículo de 1993. Y además la fecha límite para la conferencia acecha. Así que por el momento lo dejaré aquí.

\section{Conclusión}

El propósito de este texto no era ni la interpretación ni la explicación, ni mucho menos una teoría general. En lugar de ello simplemente quería desarrollar algunos hechos anteriormente desconocidos sobre la longue durée de la estructura de matrimonios en la élite de Florencia, para restringir mis futuros esfuerzos interpretativos / explicativos. Los próximos pasos, más focalizados, de mi investigación estarán guiados por las tenencias esbozadas a groso modo en el estudio de este primer borrador. 
REDES- Revista hispana para el análisis de redes sociales

Vol.21,\#3, Diciembre 2011

http://revista-redes.rediris.es

KoE $10 \times 10$ TO

461320

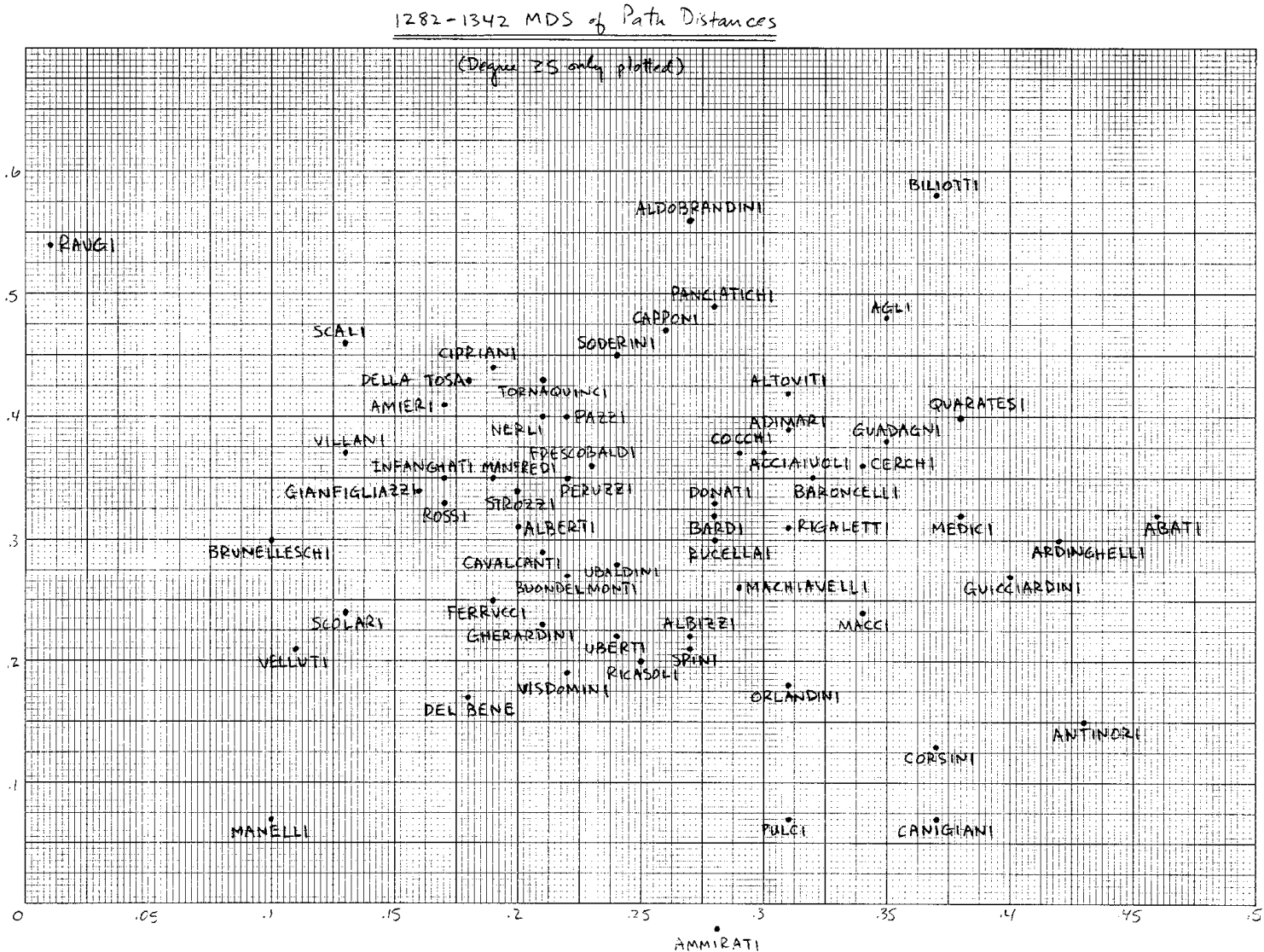

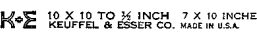

461320

SALVIATI

1343-1377 MDS of Poth Distamees

SERRAGLI

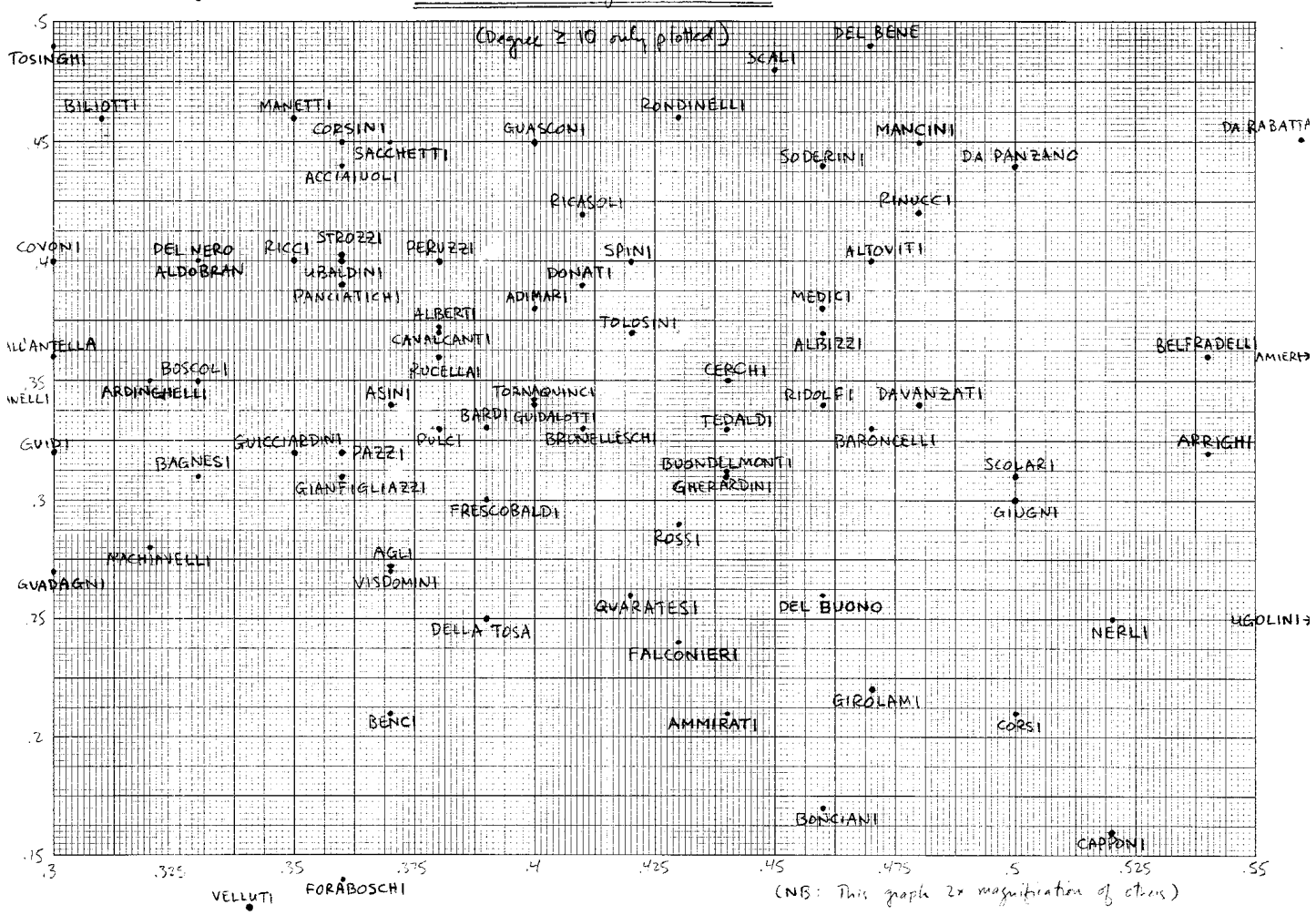


REDES- Revista hispana para el análisis de redes sociales

Vol.21,\#3, Diciembre 2011

http://revista-redes.rediris.es
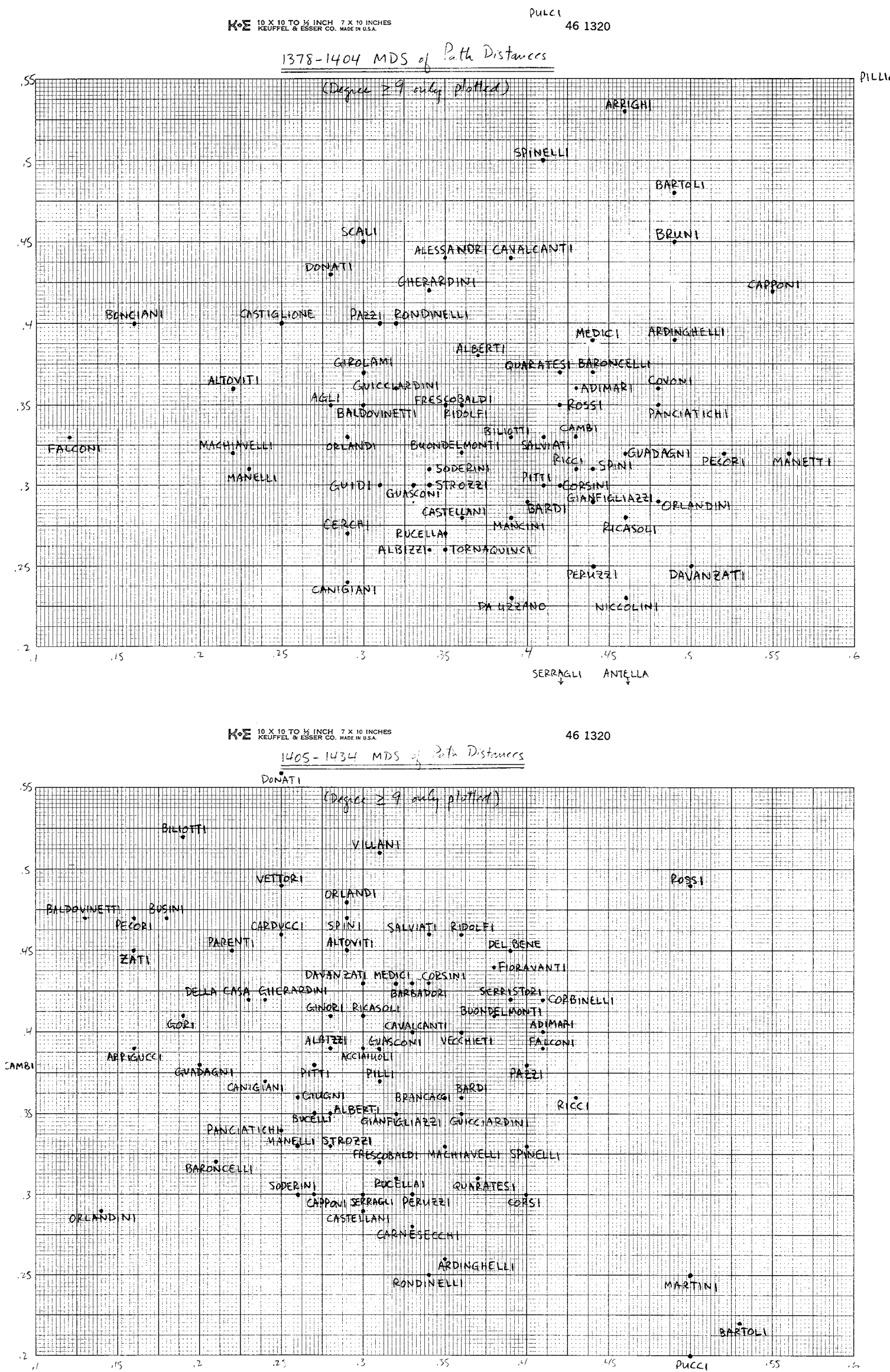
REDES- Revista hispana para el análisis de redes sociales

Vol.21,\#3, Diciembre 2011

http://revista-redes.rediris.es

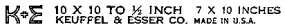

461320

$1435-1464$ MOS of Path Detaraces

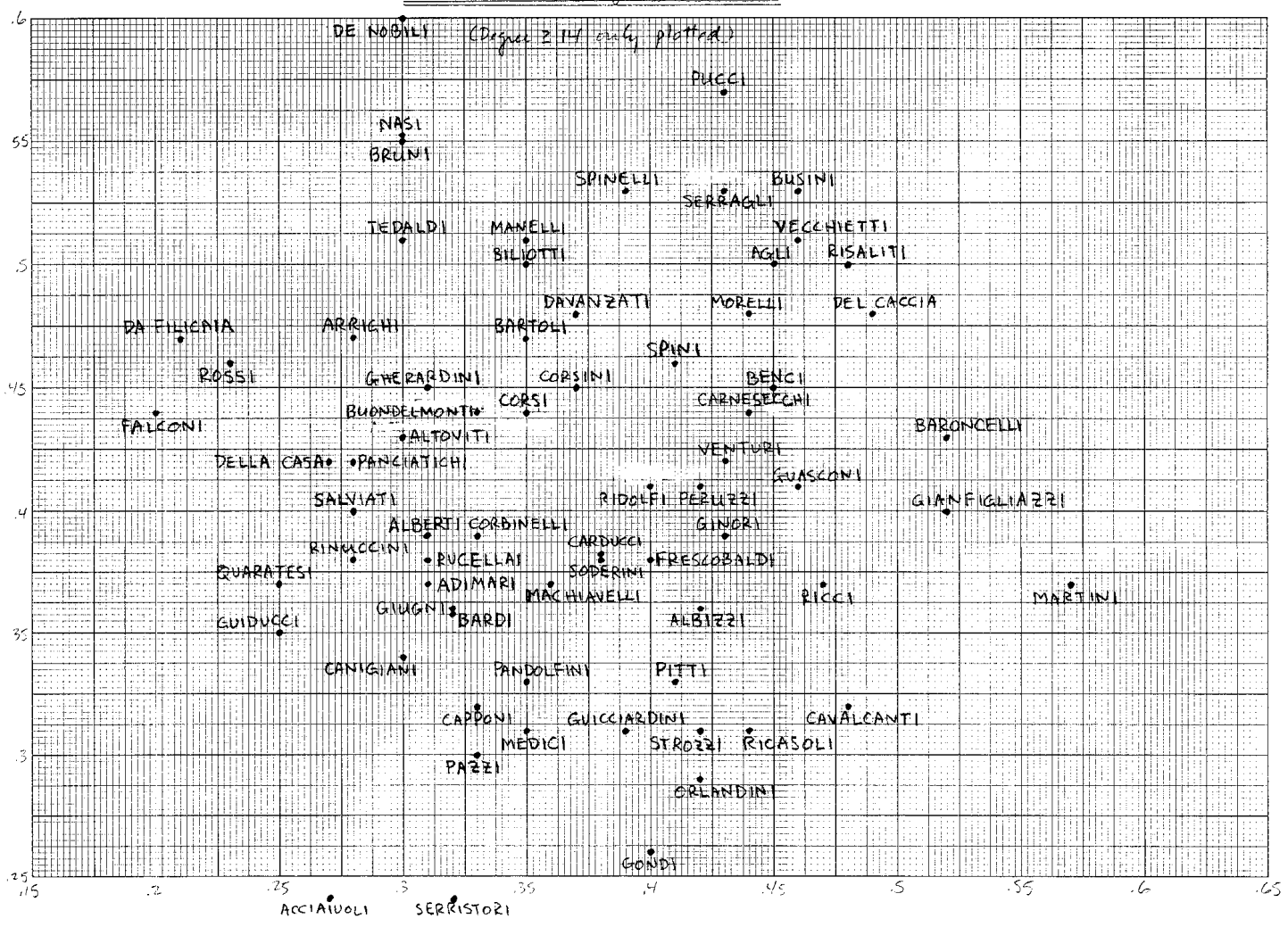

KFEE KEUFFLL $10 \times 10$ TO

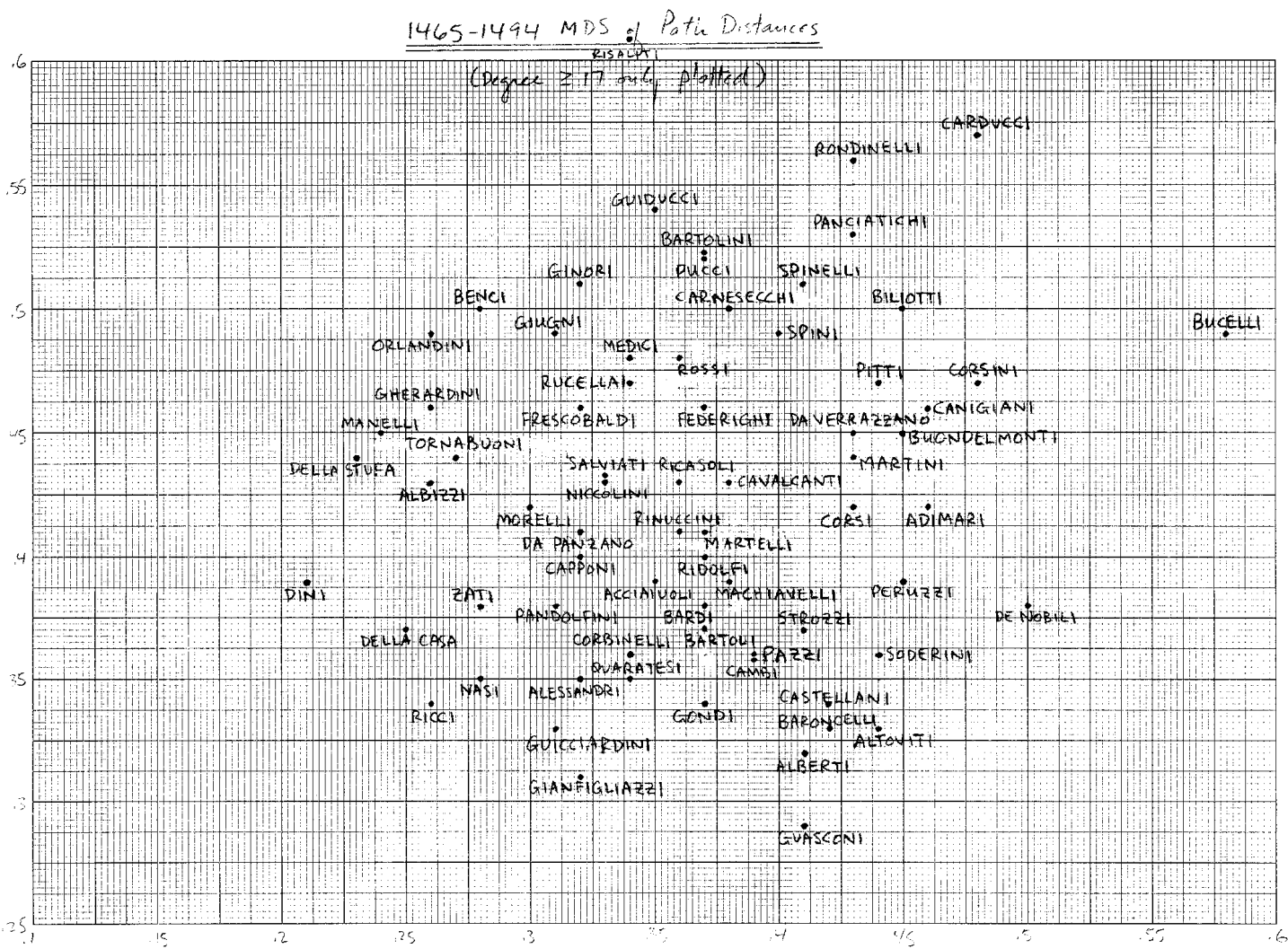

